\title{
Research Paper: Health Tourism System Development Using Entrepreneurial Management Approach in the COVID-19 Pandemic Era
}

 \\ 1. Department of Entrepreneurship Management, School of Management and Economics, Science and Research Branch, Islamic Azad University, Tehran, Iran. \\ 2. Department of Business, School of Entrepreneurship, University of Tehran, Tehran, Iran. \\ 3. Department of Management Sciences and Health Economics, School of Public Health, Tehran University of Medical Sciences, Tehran, Iran.
}

\begin{tabular}{|c|c|}
\hline 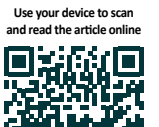 & $\begin{array}{l}\text { Citation Dehghan R, Reshadatjoo H, Talebi K, Dargahi H. Health Tourism System Development Using Entrepreneurial } \\
\text { Management Approach in the COVID-19 Pandemic Era. Journal of Research \& Health. 2021; 11(4):251-260. http://dx.doi. } \\
\text { org/10.32598/JRH.11.4.1860.1 }\end{array}$ \\
\hline 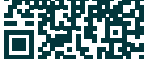 & doi)http://dx.doi.org/10.32598/JRH.11.4.1860.1 \\
\hline
\end{tabular}

\section{(i) (\$)}

Article info:

Received: 20 Dec 2020

Accepted: 08 Apr 2021

Publish: 01 Aug 2021

\section{Keywords:}

Health tourism industry, Entrepreneurial management, Coronavirus

\section{A B S T RACT}

Background: Health tourism uses a set of services that promote the health and spirit of individuals through medical care. Entrepreneurship is a process of exploring and using value creation opportunities in the economic, cultural, social, and health sectors. The present study was done to investigate the development of Iran's health tourism system based on Stevenson's entrepreneurial management model and determine entrepreneurial opportunities during the COVID-19 outbreak.

Methods: This descriptive quantitative research was conducted by the field study (survey) method, using a standardized and localized questionnaire from Stevenson's entrepreneurial management model to examine the views of health tourism specialists as the statistical population of the study. Using the snowball sampling method, 357 health tourism specialists, university professors, and health system managers participated in this study from 2018 to 2020. The collected data were recorded in PLS Smart software and their analysis was performed using descriptive and inferential statistics.

Results: The findings indicated that all six components of Stevenson's entrepreneurial management had a significant effect on the health tourism industry's development. Strategic orientation and commitment to opportunities (path coefficient: 0.83 ) had the maximum effect, while the reward philosophy (path coefficient: 0.41 ) had the minimum effect on developing the health tourism industry.

Conclusion: The average status of Stevenson's entrepreneurial management dimensions in the health tourism industry was evaluated. Some of these factors (strategic orientation and commitment to opportunities) were obviously more favorable than others. Proper entrepreneurial strategies and the use of situations can provide good opportunities in health tourism.

\footnotetext{
* Corresponding Author:

Hamideh Reshadatjoo, PhD.

Address: Department of Entrepreneurship Management, School of Management and Economics, Science and Research Branch, Islamic Azad University, Tehran, Iran. Phone: +98 (912) 3032057

E-mail: reshadatjoo@srbiau.ac.ir
} 


\section{Introduction}

he concept of entrepreneurship was first invented in French as Entreprendre,

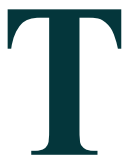
meaning interferer [1] or in English, from the term "to undertake", and was translated into English by Stewart Male in 1848. This term was first introduced as the employer in Persian and then, entrepreneurship was defined as a person who takes responsibility [2]. According to Dracker, although several years have passed since introducing the concept of entrepreneurship, recent environmental conditions have led to a revolution in entrepreneurship [3]. According to Schumpeter, entrepreneurship is a driver for development, and in many countries, it is believed that entrepreneurship plays a key role in economic development [4]. As a result, many developed and developing countries have accepted the entrepreneurship development of the tourism industry as an effective approach for the prosperity of their economy [5].

Some studies have indicated that the tourism industry is the most efficient industry in the world after the oil and automobile industries [6]. The tourism industry plays a pivotal role in improving employment in any society [7]. Tourism in general and health tourism, in particular, is the most significant industrial sector and one of the most significant global phenomena in the 21 st century. Tourism promotes development, stimulates economic development, revives cultural heritage, and unites nations [8]. The tourism industry is divided into various sectors. Health and medical tourism is one of the subsets of this industry, which has developed over time. According to the World Bank, the third area of capitalism in the world is related to this type of tourism [9].

Based on the United Nations World Tourism Organization (2019), the value of the global medical tourism market in 2018 was about $\$ 16761$ million and is expected to reach about $\$ 27247.6$ million by 2024 . In addition, the reports from VISA and Oxford Economics indicated that almost 11 million medical tourists create a market value of $\$ 100$ billion annually, representing a large market with a growth rate of $25 \%$ per year [10]. In terms of economy, the exchange revenue of Iran depends on crude oil exports to other countries. However, Iran is attempting to invest in tourism as a source of income to reduce its dependency on the oil industry. Health tourism forms one of these programs. Iran has a very high potential in lowcost medical care, internationally recognized physicians, successful surgical procedures (liver, heart, etc.) at the international level, and low waiting time for treatment [11].
Stevenson et al. (1983) described entrepreneurial management as the process of identifying or making an opportunity to create value through innovation and opportunity pursuit. Stevenson stated that entrepreneurial management, defined as a set of opportunity-based management practices, can help society and contribute to societal level value. Stevenson's entrepreneurial management model comprises six dimensions: strategic orientation, resource orientation, management structure, reward philosophy, growth orientation, and entrepreneurial culture [12].

The International Union of Tourism Organizations (1973) defined the concept of health tourism as obtaining health care using the natural resources of the Earth, especially mineral water and climate. Health tourism consists of three parts of health tourism, including nature tourism and rural tourism, health care tourism, including spa and rehabilitation, and medical tourism, including surgeries and treatments [13]. From the perspective of entrepreneurial management, health tourism provides an opportunity for creating unique and specialized jobs.

International healthcare travelers in the past aimed at seeking a treatment, which was unavailable in the country of origin. New medical tourism mainly includes private hospitals, clinics, or private healthcare providers, relying on the number of patients to support and fund their services $[14,15]$. In the health tourism market, recognizing the opportunities of entrepreneurs is vital. The challenges in the health tourism industry and prevailing environmental conditions (COVID-19 epidemic) are the main reasons for conducting this research. Hence, it was analyzed based on Stevenson's dimension, which analyzes the managers' attitudes and insights.

Coronavirus; The most significant challenge for entrepreneurship in the health tourism development

The World Health Organization (WHO) declared COVID-19 as an epidemic on March 11, 2020 [16]. Due to the comprehensive presence of entrepreneurship in the global business environment, it is highly important to understand the significance of the effect of the COVID-19 crisis on the economy [17, 18]. Global research has indicated the significance of entrepreneurship during an economic crisis, like the current COVID-19 epidemic.

Factors, such as entrepreneurial personality, entrepreneurial spirit, humility, empathy, innovation, opportunity recognition, social entrepreneurship, commitment to a goal, domestic investment, small business entrepreneurship, new business models, and entrepreneurship can 
reduce the problems in the economy in such difficult conditions because the conditions have changed and the future is uncertain [19].

There is a diverse range of entrepreneurs. People who only have to have a business to live, there is no discussion of opportunity and interest here, and it is only a matter of living. That is, they start their businesses based on the need for work and the necessity of life. They have no other way. necessity-based entrepreneurship [20].

Despite the entrepreneurial orientation and individual characteristics, global studies have evaluated the effect of external power on creating new investments. Such studies have identified the effect of entrepreneurial actions on the results obtained from external conditions, like new technologies, economic or natural environments, or even epidemics, such as COVID-19. It has been shown that the most obvious mechanism, by which COVID-19 creates business opportunities is to create, expand, and replace demand. Furthermore, the epidemic can lead to the production of yield or services in start-ups [21].

Isenberg and Schultz have indicated an exponential increase in opportunities for entrepreneurs in epidemics. Social isolation has accelerated great opportunities, such as flexible manufacturing, online education, emergency management, healthcare analytics, geriatrics, telemedicine, digital micro-investment, supply chain flexibility for the required items, multiplayer entertainment platforms, telecommunication technology support, and even the development of smarter cities due to epidemics [22]. With the significant increase in entrepreneurial opportunities in the COVID-19 epidemic during the economic crisis, entrepreneurship may be considered as an anonymous hero to pave the way for the difficulties created by these crises for societies. [19].

Considering the COVID-19 epidemic and the cessation of the health tourism industry, this opportunity should be explored to identify the challenges and capacities of the health tourism industry to use its benefits in the economy and employment in Iran. Entrepreneurship should focus on the existing resources, problems, and opportunities. What works in one area may not work in another area. The causes for the failure of many societies in the field of entrepreneurship should be sought within themselves. Thus, any country can be the founder of a successful entrepreneurial system by considering its geographical location, social, cultural, economic, and political conditions.

\section{Methods}

\section{Approach and purpose}

This study was of a quantitative type with a descriptive approach conducted by field method or survey that investigated the development of Iran's health tourism system based on Stevenson's model and assessed entrepreneurial chances in the COVID-19 pandemic in Iran. The research components were based on each dimension of the entrepreneurial management approach (strategic orientation, resource orientation, management structure, reward philosophy, growth orientation, and entrepreneurial culture).

\section{Questionnaire and sampling}

The main question of the research was to evaluate the health tourism situation in Iran using Stevenson's entrepreneurial management approach, based on which the six dimensions of the model and the sub-questions of the research were adjusted. A standardized and localized questionnaire based on Stevenson's entrepreneurial management model was used to evaluate the views of health tourism activists as the statistical population of the study.

The target group consisting of 382 people was approved to distribute the questionnaire to, based on snowball sampling from 2019-2020, while a total of 357 people participated. The prepared questionnaires comprised 22 questions assessing health tourism industry activists. This questionnaire was designed based on the Likert scale from "very low" with a score of 1 to "very high" with a score of 5. After confirming the validity and reliability of the questionnaire, the research model was fitted using structural equation modeling in LISREL software. To this end, the fit indices of the structural equation model were used.

\section{Statistical analysis}

In this study, divergent validity was determined by Fornell and Larcker method. The Average Variance Extracted (AVE) must be greater than the square of the correlation coefficient of each component with other components [23]. The reliability of the questionnaire was determined by Cronbach's alpha and Composite Reliability (CR). If $\mathrm{CR}$ and Cronbach's alpha for each latent variable is higher than 0.7 , the reliability of that latent variable can be considered desirable [24]. Afterward, the data obtained from the questionnaires were analyzed in two sections: descriptive findings and inferential findings.

In the first section, the frequency distribution of demographic variables and descriptive indicators of research 
Table 1. Mean \pm SD, skewness, and kurtosis of the entrepreneurial management model components

\begin{tabular}{cccc}
\hline Component & Mean \pm SD & Skewness & Kurtosis \\
\hline Strategic orientation and commitment to opportunities & $3.35 \pm 0.88$ & -0.340 & -0.221 \\
\hline Commitment to resources and control & $3.24 \pm 0.71$ & -0.161 & 0.300 \\
Management structure & $2.86 \pm 0.77$ & -0.035 & -0.193 \\
\hline Growth orientation & $3.02 \pm 0.83$ & -0.035 & -0.206 \\
Reward philosophy & $3.01 \pm 0.79$ & -0.233 & -0.111 \\
\hline Entrepreneurial culture & $2.94 \pm 0.82$ & 0.001 & -0.254 \\
\hline
\end{tabular}

variables were presented. Subsequently, in the latter section, a confirmatory factor analysis of the questionnaire indicators was performed and the research questions were answered. Herein, two indices of skewness and elongation were used to evaluate the normal distribution of variables. Confirmatory factor analysis was used to determine whether the questions and indicators were valid. The AVE and load factor were used to measure the convergent validity. Finally, the collected data were recorded in PLS Smart software, and its analysis was conducted using descriptive statistics methods, including the frequency of demographic variables and descriptive indicators of the research variables and inferential statistics.

\section{Results}

As indicated in Table 1, the average of strategic orientation and commitment to opportunities, commitment to resources and control, Growth Orientation, and reward philosophy were greater than 3 , while the average of management structure and entrepreneurial culture were below 3 . In this study, skewness and kurtosis were used to evaluate the normal distribution of variables.

Table 2 indicates the reliability of the questionnaire constructs. The questionnaire had good reliability since the numerical value of the composite reliability index and Cronbach's alpha for all constructs was greater than 0.7 .

As Table 3 indicates, the numerical value of the skewness index for all variables was in the range $(+2,-2)$ and the numerical value of kurtosis was in the range $(+3,-3)$. Thus, all variables followed the normal distribution.

Table 3 illustrates that the AVE was greater than the square of the correlation coefficient of each component with the other components of Stevenson's entrepreneurial management approach resulting in the divergent va- lidity. Table 3 also indicates the reliability of the questionnaire constructs, which is considered to be a decent one due to the numerical value and the presence of convergent validity.

Table 4 depicts that the Chi-square ratio to the degree of freedom was 1.58 and less than 5 , and the root mean square error of approximation was 0.065 and less than 0.08 . The goodness of fit index, the normal fit index, the non-normal fit index, the goodness of fit index, and the adjusted goodness of fit index were greater than 0.9. Therefore, the model showed a very good fit and was approved.

As shown in Table 5, the t statistic for all six variables was higher than the significance threshold of 1.96. In other words, all six components of Stevenson's entrepreneurial management had a significant effect on the entrepreneurship development of the health tourism industry. Furthermore, considering the reported path coefficient, strategic orientation and commitment to opportunities had the maximum effect, and reward philosophy had the minimum effect on the health tourism industry.

The developed model in this research is displayed in Figure 1. Stevenson's entrepreneurial management approach is an important dimension of the attitude and insight required in senior management thinking. Regarding the category of management of industry, the dimensions mentioned can lead to non-entrepreneurial decisions in management if not considered or neglected. Stevenson's entrepreneurial management model emphasizes managerial decision-making, concentrating on creating opportunities and values in regard to changing the approach of senior managers. 
Table 2. Results of factor analysis of Stevenson's entrepreneurial management approach

\begin{tabular}{|c|c|c|c|c|c|}
\hline Questions & Load Factor & Significance Number & AVE & $\begin{array}{c}\text { Composite Reli- } \\
\text { ability }\end{array}$ & Cronbach's Alpha \\
\hline \multicolumn{6}{|c|}{ Strategic orientation and commitment to opportunities } \\
\hline 1 & 0.69 & 14.32 & & & \\
\hline 2 & 0.90 & 20.85 & 0.68 & 0.86 & 0.89 \\
\hline 3 & 0.76 & 16.32 & & & \\
\hline \multicolumn{6}{|c|}{ Commitment to resources and control } \\
\hline 4 & 0.76 & 15.67 & & & \\
\hline 5 & 0.77 & 15.96 & 0.58 & 0.81 & 0.84 \\
\hline 6 & 0.66 & 13.15 & & & \\
\hline \multicolumn{6}{|c|}{ Management structure } \\
\hline 7 & 0.67 & 13.60 & & & \\
\hline 8 & 0.59 & 11.64 & & & \\
\hline 9 & 0.71 & 14.55 & & & \\
\hline & & & 0.49 & 0.85 & 0.88 \\
\hline 10 & 0.70 & 14.27 & & & \\
\hline 11 & 0.77 & 16.50 & & & \\
\hline 12 & 0.72 & 15.02 & & & \\
\hline \multicolumn{6}{|c|}{ Growth orientation } \\
\hline 13 & 0.65 & 12.37 & & & \\
\hline 14 & 0.68 & 13.85 & 0.50 & 0.75 & 0.78 \\
\hline 15 & 0.79 & 17.21 & & & \\
\hline \multicolumn{6}{|c|}{ Reward philosophy } \\
\hline 16 & 0.71 & 14.69 & & & \\
\hline 17 & 0.73 & 15.22 & & & \\
\hline & & & 0.52 & 0.81 & 0.82 \\
\hline 18 & 0.74 & 15.53 & & & \\
\hline 19 & 0.69 & 13.07 & & & \\
\hline \multicolumn{6}{|c|}{ Entrepreneurial culture } \\
\hline 20 & 0.71 & 14.38 & & & \\
\hline 21 & 0.69 & 13.21 & 0.50 & 0.75 & 0.79 \\
\hline 22 & 0.73 & 15.20 & & & \\
\hline
\end{tabular}

AVE: Average Variance Extracted. 
Table 3. Results of divergent validity of factor analysis

\begin{tabular}{|c|c|c|c|c|c|c|c|}
\hline Stevenson's Entrepreneurial Management & 1 & 2 & 3 & 4 & 5 & 6 & AVE \\
\hline 1- Strategic orientation and commitment to opportunities & & 0.29 & 0.41 & 0.32 & 0.48 & 0.39 & 0.68 \\
\hline 2- Commitment to resources and control & 0.29 & & 0.43 & 0.47 & 0.51 & 0.28 & 0.58 \\
\hline 3- Management structure & 0.41 & 0.43 & & 0.33 & 0.38 & 0.42 & 0.49 \\
\hline 4- Growth orientation & 0.32 & 0.47 & 0.33 & & 0.44 & 0.41 & 0.50 \\
\hline 5- Reward philosophy & 0.48 & 0.51 & 0.38 & 0.44 & & 0.35 & 0.52 \\
\hline 6- Entrepreneurial culture & 0.39 & 0.28 & 0.42 & 0.41 & 0.35 & & 0.50 \\
\hline
\end{tabular}

AVE: Average Variance Extracted.

\section{Discussion}

Six components related to Stevenson's entrepreneurship model were evaluated. Based on the results, strategic orientation and commitment to opportunities had the highest average and management structure had the lowest average. The status of six dimensions related to entrepreneurial management indicated the average status of these dimensions in health tourism. Nevertheless, some factors, such as strategic orientation and commitment to opportunities were more favorable than others; however, no difference was observed between these factors in terms of the desirability of each factor.

This study revealed that the status of health tourism depends on various components. Considering the value of the determined path coefficient, strategic orientation and commitment to opportunities, and management structure had the greatest effect on the health tourism industry development. Thus, the elements of the entrepreneurial process in the health tourism system are seemingly separated but interrelated.

An appropriate and entrepreneurial management structure with the strategic orientation of managers can provide appropriate opportunities in health tourism. Entrepreneurship development should be considered as a comprehensive and sustainable process and consider all economic, cultural, and social factors simultaneously. Thus, the policies, which are formulated for entrepreneurship development can lead to the tourism industry development by considering all its dimensions. Kaur studied entrepreneurship development in the medical tourism industry in India [24]. This study analyzed three chains of Indian hospitals, providing medical services to foreign medical tourists. The results indicated that these hospitals provide medical services to foreign patients in accordance with international standards. In addition, the low cost of treatment, high quality of care, advanced infrastructures, and advanced technology used by Indian

Table 4. Fit indices of the structural equation model

\begin{tabular}{cccc}
\hline Fitness Index & Abbreviations & Good Fit & Calculated Value \\
\hline $\begin{array}{c}\text { Chi-square ratio to degree of } \\
\text { freedom }\end{array}$ & $\chi^{2} / \mathrm{df}$ & $0 \leq \mathrm{x}^{2} / \mathrm{df} \leq 5$ & 1.58 \\
$\begin{array}{c}\text { Root mean square error of } \\
\text { approxima-tion } \\
\text { Goodness of fit in-dex }\end{array}$ & RMSEA & $0 \leq \mathrm{RMSEA} \leq 0.08$ & 0.065 \\
\hline $\begin{array}{c}\text { Adjusted goodness of fit index } \\
\text { Incremental fit in-dex }\end{array}$ & $\mathrm{GFI}$ & $0.90 \leq \mathrm{GFI} \leq 1$ & 0.95 \\
\hline Normal fit index & $\mathrm{AGFI}$ & $0.90 \leq \mathrm{AGFI} \leq 1$ & 0.89 \\
\hline Non-normal fit in-dex & $\mathrm{NFI}$ & $0.90 \leq \mathrm{IFI} \leq 1$ & 0.91 \\
\hline comparative fit index & $\mathrm{NNFI}$ & $0.90 \leq \mathrm{NFI} \leq 1$ & 0.90 \\
\hline
\end{tabular}


Table 5. Effect of Stevenson's entrepreneurial management dimensions on the health tourism industry development

\begin{tabular}{|c|c|c|c|}
\hline Path & Path Coefficient & T Statistics & Result \\
\hline $\begin{array}{l}\text { Strategic orientation and commitment to opportunities }->\text { Entrepreneurship devel- } \\
\text { opment of health tourism industry }\end{array}$ & 0.83 & 13.58 & Confirmed \\
\hline $\begin{array}{l}\text { Commitment to resources and control }->\text { Entrepreneurship development of health } \\
\text { tourism industry }\end{array}$ & 0.50 & 4.46 & Confirmed \\
\hline Management Structure -> Entrepreneurship development of health tourism industry & 0.77 & 9.62 & Confirmed \\
\hline Growth Orientation -> Entrepreneurship development of health tourism industry & 0.47 & 3.89 & Confirmed \\
\hline Reward philosophy -> Entrepreneurship development of health tourism industry & 0.41 & 2.94 & Confirmed \\
\hline Entrepreneurial Culture -> Entrepreneurship development of health tourism industry & 0.43 & 3.15 & Confirmed \\
\hline
\end{tabular}

met

medical service providers played an essential role in improving medical tourism and developing entrepreneurship in India [25].

Kahrizi et al. conducted a study to identify the barriers (and their levels and interactions) to entrepreneurship in medical and health tourism in Kermanshah [2]. These factors included cultural barriers to tourism development and barriers to cooperation between the public and private sectors. Cultural barriers to tourism development greatly affect the health tourism entrepreneurship devel- opment in Kermanshah [2]. In another study by Azizi and Zahedi, factors, such as high costs, no adequate advertising, and lack of human resources were reported as the most significant barriers to health tourism in Yazd province [25].

Soltaninejad and Vosoughi reported the entrepreneurial potentials in Kerman province and found that tourism is highly effective in entrepreneurship development by creating new economic opportunities, and entrepreneurship is associated with tourism development and the increase in

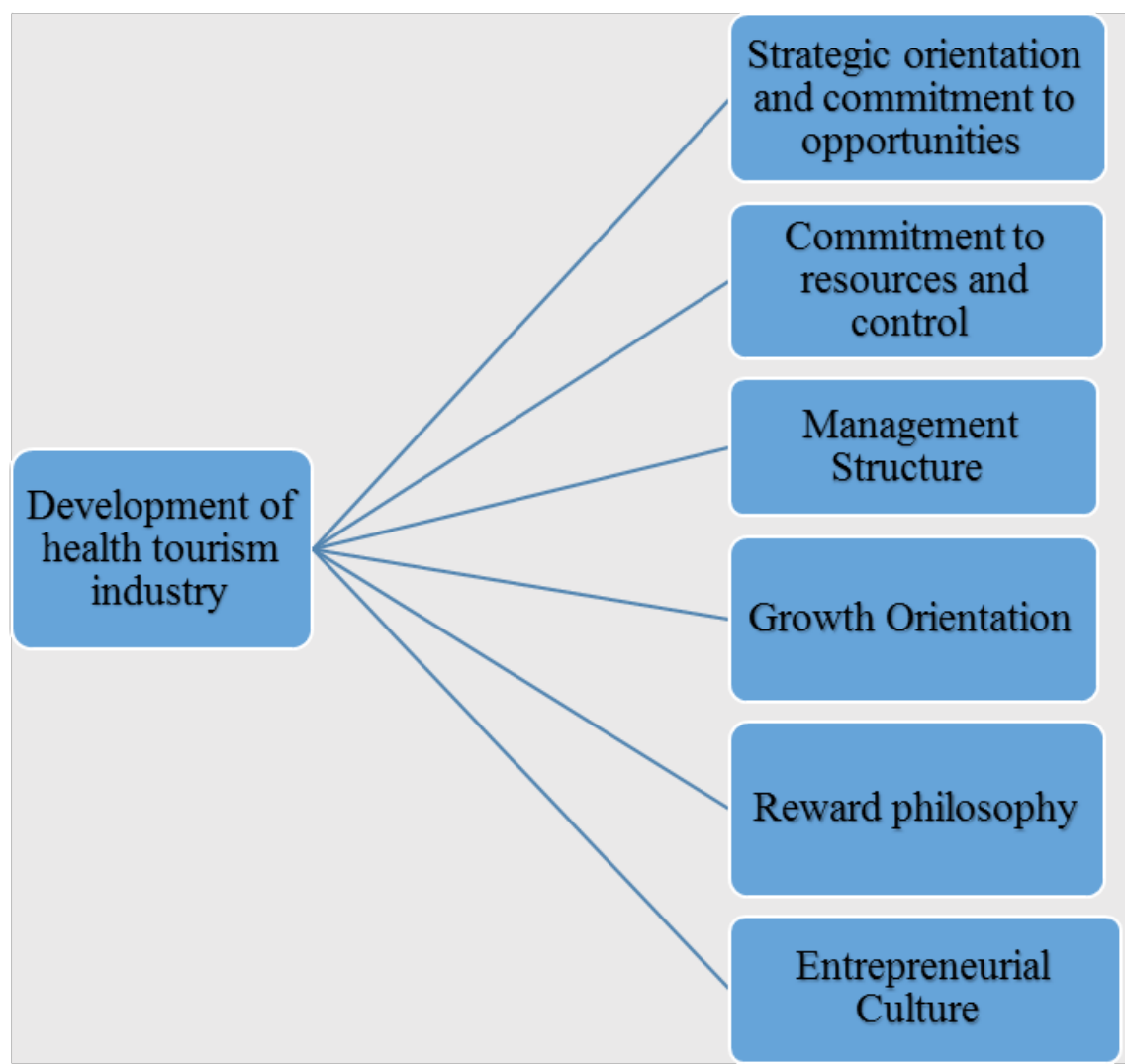

Figure 1. Conceptual model of the research 
new demands for different types of tourism [26]. Their results are consistent with those of the present study, which considered a commitment to opportunities as the most critical factor in the health tourism industry development.

Asadi et al. examined the internal factors affecting the health tourism development and indicated that the most effective factor in the health tourism industry development included the decisions made in the field of marketing and advertising, security, experts in various medical fields, and the increased number of medical centers. Human resources and the skill of the medical staff are important factors for health tourism [27], which are some of the main factors of the entrepreneurial management structure.

In addition, Momeni et al. examined the factors hindering medical tourism development in East Azerbaijan province [28]. They identified 10 factors as the main obstacles to the medical tourism development in East Azerbaijan, including marketing, international relations, cultural issues, communications, medical centers, international patient transfer, brokerage, structural issues, management issues, and policy. Their results are consistent with those of the present study as the introduction of commitment factors to the resources and structure of entrepreneurial management were introduced as the factors affecting the implementation of a successful health tourism planning system in Iran.

The findings of this study, obtained using Stevenson's entrepreneurial management model, indicated the effect of strategic orientation and commitment to opportunities on the health tourism industry development. Iran has a high capacity to produce and provide tourism services. Investing with appropriate entrepreneurial patterns can realize these capacities as a source of foreign exchange. The economic crisis caused by the outbreak of COVID-19 has provided many opportunities for the development of health tourism entrepreneurs. Due to the health tourism capacities in Iran, such as convenient geographical location, low-cost services (medical services, health care, nature tourism, etc.), appropriate equipment, and qualified physicians, Iran can be the center of health tourism in Asia in post-COVID-19conditions. Health tourism development and the implementation of effective entrepreneurial management require planning in the field of tourism that can lead to the development of the economic market. International trade is a field with intense competition, which can be expected to succeed by adopting appropriate strategies.

Entrepreneurship, a crucial help to the countries' economy, plays a vital role in their economic development by using innovation, improving production, and providing services. Health tourism as a valuable source of income generation and job creation at the national level can be a factor in entrepreneurship development. Entrepreneurs should take full advantage of the opportunities available during the corona crisis to develop entrepreneurial activities. Moreover, politicians must take notice of the community employment issue and health tourism development in addition to solving the problem of nonemployment to encourage entrepreneurship in the country and finally help its growth. Because unemployment and lack of employment-generating resources are some socio-economic problems in Iran, strategic planning in health tourism can be an appropriate solution for entrepreneurship and the creation of more jobs.

The main limitations of the research were the complexity of the type of trade in the health tourism industry and its multidisciplinary nature and specialization, along with the limited number of people with a simultaneous interdisciplinary specialization in tourism, health sciences, and entrepreneurship, and also conducting the research during the COVID-19 outbreak. The pandemic caused the research to be conducted through cyberspace without face-to-face interactions between the researcher and the target community.

\section{Conclusion}

According to the results of the present study, the six dimensions of the entrepreneurial management approach were effective on the development of the health tourism industry and the creation of appropriate opportunities in accordance with the country's conditions. The lack of employment resources is one of the important economic problems of Iran. Entrepreneurship development in health tourism requires the appropriate context of cultural, social, economic conditions and the cooperation of tourism management systems with administrative and financial structures and other government support mechanisms. Also, based on Stevenson's entrepreneurial management model, the development of entrepreneurship in the health tourism industry creates more valuable opportunities in managerial decisions. All institutions of health tourism should work in an integrated way with all possible potentials using the existing opportunities and entrepreneurial management structure to develop entrepreneurship in the COVID-19 and post-COVID-19 conditions.

\section{Ethical Considerations}




\section{Compliance with ethical guidelines}

This study was approved by the Ethics Committee of Science and Research Branch, Islamic Azad University, Tehran (Code: 950334438).

\section{Funding}

This study was exracted from the $\mathrm{PhD}$. dissertation of first author at the Department of Entrepreneurship Management, School of Management and Economics, Science and Research Branch, Islamic Azad University, Tehran.

\section{Authors' contributions}

All authors equally contributed to preparing this article.

\section{Conflict of interest}

The authors declared no conflict of interest.

\section{Acknowledgments}

We would like to thank Dr. Masoumeh Nomani, a specialist in biotechnology and biometric genetics, and Dr. Farnia Velayati, who helped compile the scientific content and analysis of this study.

\section{References}

[1] Karbasi A, Sherafat M, Valadkhani M, Azim Zadegan H. [Review of entrepreneurship literature (Persian)]. Industry Quarterly. 2002; 33. https://www.sid.ir/Fa/Journal/ViewPaper.aspx?ID=143775

[2] Kahrizi O, Naderi N, Rezaei B, Olya H. The barriers against the entrepreneurship development of medical and healthcare tourism industry: Evidence from Kermanshah, Iran. Int J Health Life Sci. 2020; 6(2):e102036. [DOI:10.5812/ijhls.102036]

[3] Russell R, Faulkner B. Entrepreneurship, chaos and the tourism area lifecycle. Ann Tour Res. 2004; 31(3):556-79. [DOI:10.1016/j.annals.2004.01.008]

[4] Imeni Gheshlagh S, Hashemi S. [The role of entrepreneurship in the sustainable development of tourism (Persian)]. Work and Society. 2009; (106-107):95-106. https:/ /www.sid. $\mathrm{ir} / \mathrm{Fa} /$ Journal/ViewPaper.aspx?ID=166486

[5] Chhabra D, Healy R, Sills E. Staged authenticity and heritage tourism. Ann Tour Res. 2003; 30(3):702-19. [DOI:10.1016/ S0160-7383(03)00044-6]

[6] Tosun C. Challenges of sustainable tourism development in the developing world: The case of Turkey. Tour Manage. 2001; 22(3):289-303. [DOI:10.1016/S0261-5177(00)00060-1]

[7] Suess C, Baloglu S, Busser JA. Perceived impacts of medical tourism development on community wellbeing. Tour Manage. 2018; 69:232-45. [DOI:10.1016/j.tourman.2018.06.006]
[8] Dimitrov NV, Magdiceva-Sopova M, Josevski D. Role of the modern entrepreneurship in the development of the health tourism in Republic of Macedonia. Int J Bus Manage Invent. 2016; 5(10):102-6. https://eprints.ugd.edu.mk/id/ eprint/16628

[9] Arabshahi A, Ariyanfar M. [Health tourism and tourism development; reviewing the potential and capabilities of Iran in health tourism and medical - curative tourism (Persian)] Geogr J Tour Space. 2014; 3(9): 133-52. https:/ /www.sid.ir/ en/journal/ViewPaper.aspx?id $=410681$

[10] Dang HS, Nguyen TM, Wang CN, Day JD, Dang TMH. Grey system theory in the study of medical tourism industry and its economic impact. Int J Environ Res Public Health. 2020; 17(3):961. [DOI:10.3390/ijerph17030961]

[11] Jabbari A, Rahimi Zarchi MK, Kavosi Z, Shafaghat T, Keshtkaran A. The marketing mix and development of medical tourism in Shiraz. Mater Sociomed. 2013; 25(1):32-6. [DOI:10.5455/msm.2013.25.32-36] [PMID]

[12] Brown TE, Davidsson P, Wiklund J. An operationalization of Stevenson's conceptualization of entrepreneurship as opportunity-based firm behavior. Strateg Manage J. 2001; 22(10): 953-68. [DOI:10.1002/smj.190]

[13] Uygun M, Ekiz E. An overview of health tourism within the context of Turkey's tourism strat egy (2023). J Hosp Tour. 2016; 14(1):18-26. https:// d1wqtxts1xzle7.cloudfront.net/49690938/_\&Key-Pair$\mathrm{Id}=$ APKAJLOHF5GGSLRBV4ZA

[14] Fisher G, Hughes R, Griffin R, Pustay M. International Business. Melbourne: Pearson Education Australia; 2006.

[15] Liguori E, Winkler C. From offline to online: Challenges and opportunities for entrepreneurship education following the COVID-19 pandemic. Entrep Educ Pedagogy. 2020; 3(4):346-51. [DOI:10.1177/2515127420916738]

[16] Foss NJ. Behavioral strategy and the COVID-19 disruption. J Manage. 2020; 1-14. [DOI:10.2139/ssrn.3635998]

[17] Ratten V. Coronavirus (Covid-19) and entrepreneurship: Cultural, lifestyle and societal changes. J Entrep Emerg Econ; 2020. [DOI:10.1108/JEEE-06-2020-0163./]

[18] Maritz A, Perenyi A, de Waal G, Buck CH. Entrepreneurship as the unsung hero during the current COVID-19 economic crisis: Australian perspectives. Sustainability. 2020; 12(11):4612. [DOI:10.3390/su12114612]

[19] Maddyness. 19 businesses pivoting in response to COVID-19 [Internet]. 2020 [Updated 2020 April 15]. Available from: https://www.maddyness.com/uk/2020/03/31/19businesses-pivoting-in-response-to-covid-19/

[20] Taylor K. The Covid-19 pandemic as external enabler of entrepreneurship [Internet]. 2020 [Updated 2020 May 28]. Available from: https://research.qut.edu.au/ace/2020/04/30/ covid19-pandemic-as-external-enabler-of-entrepreneurship/

[21] Isenberg D, Schultz EB. Opportunities for entrepreneurs in the pandemic and beyond [Internet]. [Updated 2020 May 28]. Available from: https://medium.com/@disen2/opportunities-for-entrepreneurs-in-the-pandemicand-beyondf92f5fa1997b

[22] Fornell C, Larcker DF. Evaluating structural equation modeling with unobserved variables and measurement error. J 
Marking Res. 1981; 18(1):39-50. [DOI:10.1177/002224378101 800104]

[23] Sobhani Fard Y. [Fundamentals and application of factor analysis and structural equation modeling (Persian)]. Tehran: Imam Sadegh University Press; 2016. https://www.gisoom. com/book/11271158/\%DA\%A9\%DB /

[24] Kaur P. Entrepreneurship in medical tourism industry. Int J Inf Mov. 2016; 1(5):22-5. http://www.ijim.in/wp-content/ uploads/2016/09/Vol-I-Issue-V-22-25-paper-4-ParneetKaur-ENTREPRENEURSHIP-IN-MEDICAL-TOURISM-INDUSTRY.pdf

[25] Azizi F, Zahedi Sh. [Assessment of the barriers to the development of health tourism in Yazd Province, Iran (Persian)] Health Inf Manage. 2016; 12(6):799-806. http://him.mui. ac.ir/index.php/him/article/view/2451

[26] Soltani neghad M, Vosoghy L. [Investigating the entrepreneurial capacities in tourism case study: Kerman Province (Persian)]. Paper presented at: National Conference on Culture, Tourism and Urban Identity. 23-24 January 2016; Kerman, Iran. https://www.sid.ir/fa/seminar/ViewPaper. aspx?ID=21727

[27] Asadi M, Basouli M, Boroumandzad Y, Derakhsh S. [Health tourism development with qualitative cognitive mapping approach (Persian)]. Payesh. 2019; 18(5):455-64. https://www. sid.ir/en/journal/ViewPaper.aspx?ID=695822

[28] Momeni K, Janati A, Imani A, Khodayari-Zarnaq R. Barriers to the development of medical tourism in East Azerbaijan province, Iran: A qualitative study. Tour Manage. 2018; 69:307-16. [DOI:10.1016/j.tourman.2018.05.007] 